\title{
Monitoring of umbilical cord blood lead levels and sources assessment among the Inuit
}

\author{
B Lévesque, J-F Duchesne, C Gariépy, M Rhainds, P Dumas, A M Scheuhammer, \\ J-F Proulx, S Déry, G Muckle, F Dallaire, É Dewailly
}

Occup Environ Med 2003;60:693-695

Analyses completed on samples collected between 1993 and 1996 showed that about $7 \%$ of 475 Invit newborns from northern Quebec (Canada) had a cord blood lead concentration equal to or greater than $0.48 \mathrm{\mu mol} / \mathrm{l}$, an intervention level adopted by many governmental agencies. A comparison between the cord blood lead isotope ratios of Invit and southern Quebec newborns showed that lead sources for these populations were different. Our investigation suggests that lead shots used for game hunting were an important source of lead exposure in the Invit population. A cohort study conducted in three Inuit communities shows a significant decrease of cord blood lead concentrations after a public health intervention to reduce the use of lead shot. Lead shot ammunition can be a major and preventable source of human exposure to lead.

F or many years, lead contamination of the environment has become a major public health preoccupation, notably concerning neurobehavioural effects during infancy and childhood.

Nunavik is a territory located in the northern part of the province of Quebec (Canada) that is inhabited by about 8000 Inuit. A previous study done in Nunavik showed that $24 \%$ of 198 women aged between 18 and 39 years had blood lead levels equal to or greater than $0.48 \mu \mathrm{mol} / \mathrm{l}(10 \mu \mathrm{g} / \mathrm{dl}),{ }^{1}$ the intervention level adopted by the Canadian authority for young children. ${ }^{2}$ Therefore, lead was a contaminant included in a cord blood monitoring programme undertaken to assess the body burden of organochlorine compounds and heavy metals in newborns in this population. We present here the results of this programme for lead and those of a subsequent investigation aimed at determining the main sources of lead exposure.

\section{METHODS}

Mothers were recruited in the two health centres of Nunavik. Almost all women approached agreed to participate in the study. In all, 475 newborns from 14 communities in Nunavik ( $59 \%$ of all births from Nunavik during the time of the study) were recruited. Following informed consent from the mothers, blood lead levels were evaluated in the umbilical cord. Sampling was done between November 1993 and December 1996. Blood lead concentrations were determined by graphite

\section{Main message}

- The ingestion of lead shot or lead fragments from game hunted with lead ammunition seems responsible for the high cord blood lead levels found in Nunavik. furnace atomic absorption spectrometry using a Perkin-Elmer instrument, with a detection limit of $0.01 \mu \mathrm{mol} / \mathrm{l}$.

Information on the mother's age, obstetric anamnesis, and tobacco consumption (yes or no) before and during pregnancy, and on the village of residence was obtained from medical files. After log transformation of the cord blood lead level data, regression analysis was performed to analyse these variables in relation to cord blood lead concentrations. Nutritional aspects, as well as haemoglobin, iron, and calcium balance were not assessed because of the exploratory nature of the monitoring and the logistical difficulties of collecting data in this area.

Blood lead isotope ratios can help identify the origin of human exposure. This was done for Nunavik newborns using a subset of 60 samples from those which had a sufficient quantity of blood. All samples $(\mathrm{n}=29)$ with high cord blood lead concentrations $(\geqslant 0.48 \mu \mathrm{mol} / \mathrm{l})$ from 11 communities were included. For each of these 29 samples, at least one randomly selected sample from the low lead level group (lower than $0.48 \mu \mathrm{mol} / \mathrm{l}$ ) of the same community were also included. Blood lead isotope ratios were therefore determined. The mean cord blood lead concentrations (geometric) and the mean ${ }^{206} \mathrm{~Pb}:{ }^{207} \mathrm{~Pb}$ ratios (arithmetic) of the high and low exposure groups of newborns were compared with each other, and with 89 randomly selected samples (at least three samples for each most exposed Inuit) taken from a survey carried out in southern Quebec during the same period. ${ }^{3}$ Comparisons were made using Student's $t$ test. The statistical significance level was set at 0.05 . The ${ }^{206} \mathrm{~Pb}:{ }^{207} \mathrm{~Pb}$ isotope ratios were evaluated by ICP-MS using a Perkin-Elmer SCIEX Elan 5000 A instrument.

\section{RESULTS}

Table 1 presents cord blood lead concentrations by community of residence. The geometric mean was $0.19 \mu \mathrm{mol} / \mathrm{l}$ (95\% confidence interval (CI): 0.18 to 0.20$)$. Thirty three newborns $(6.9 \%)$ had cord blood lead concentrations $\geqslant 0.48 \mu \mathrm{mol} / \mathrm{l}$, with eight ( $1.6 \%$ ) exceeding $0.72 \mu \mathrm{mol} / \mathrm{l}$. No significant difference was found between the community of residence and cord blood lead levels according to the $95 \%$ CI.

Of the variables analysed through multivariate analysis, only maternal age ( $\mathrm{p}<0.0001$; partial $\left.r^{2}=0.14\right)$ and tobacco smoking during pregnancy $\left(\mathrm{p}<0.001\right.$; partial $\left.r^{2}=0.05\right)$ were associated with cord blood lead concentrations.

The geometric mean of cord blood lead levels and the average ${ }^{206} \mathrm{~Pb}:{ }^{207} \mathrm{~Pb}$ ratio for the 60 Inuit newborns were respectively $0.34 \mu \mathrm{mol} / \mathrm{l}$ (95\% CI: 0.29 to 0.41 ) and 1.195 (range

\section{Policy implications}

- The use of lead ammunition should be banned for all hunting using shotguns, and the use of non-toxic alternatives should be actively promoted. 
Table 1 Cord blood lead levels by community of residence in Nunavik

\begin{tabular}{lclll}
\hline Community & $\mathrm{n}$ & $\begin{array}{l}\text { Geometric mean } \\
(\mu \mathrm{mol} / \mathrm{I})\end{array}$ & $\begin{array}{l}\text { Range } \\
(\mu \mathrm{mol} / \mathrm{I})\end{array}$ & $95 \% \mathrm{Cl}$ \\
\hline Kuvjuarapik & 16 & 0.28 & $0.08-1.02$ & 0.20 to 0.38 \\
Umiujaq & 12 & 0.17 & $0.04-0.43$ & 0.11 to 0.28 \\
Inukjuak & 47 & 0.17 & $0.01-0.64$ & 0.14 to 0.21 \\
Povungnituk & 69 & 0.22 & $0.05-1.21$ & 0.19 to 0.25 \\
Akulivik & 20 & 0.19 & $0.09-1.31$ & 0.14 to 0.25 \\
Ivujivik & 16 & 0.23 & $0.11-0.69$ & 0.17 to 0.30 \\
Salluit & 30 & 0.21 & $0.06-0.94$ & 0.17 to 0.27 \\
Kangiqsujuaq & 23 & 0.15 & $0.05-0.33$ & 0.13 to 0.18 \\
Quaqtaq & 21 & 0.19 & $0.05-0.72$ & 0.14 to 0.25 \\
Kangirsuq & 27 & 0.20 & $0.07-0.64$ & 0.16 to 0.25 \\
Aupaluk & 9 & 0.25 & $0.09-0.89$ & 0.16 to 0.40 \\
Tasiujaq & 13 & 0.19 & $0.07-0.42$ & 0.15 to 0.25 \\
Kujijaq & 90 & 0.15 & $0.04-1.01$ & 0.13 to 0.17 \\
Kangiqsualujiuaq & 38 & 0.25 & $0.07-0.77$ & 0.21 to 0.30 \\
Unknown & 44 & 0.19 & $0.02-1.28$ & 0.16 to 0.24 \\
Total & 475 & 0.19 & $0.01-1.31$ & 0.18 to 0.20 \\
\hline
\end{tabular}

1.166-1.230; 95\% CI: 1.190 to 1.200$)$. For the high and low exposed Inuit groups, lead levels were $0.62 \mu \mathrm{mol} / \mathrm{l}$ (95\% CI: 0.57 to 0.67 ) and $0.20 \mu \mathrm{mol} / \mathrm{l}$ (95\% CI: 0.17 to 0.23 ), respectively. The difference was significant $(p \leqslant 0.0001)$. For these two samples, the average ${ }^{206} \mathrm{~Pb}:{ }^{207} \mathrm{~Pb}$ ratios were 1.199 (range 1.166-1.230; 95\% CI: 1.192 to 1.205 ) and 1.192 (range 1.174-1.212; 95\% CI: 1.187 to 1.196). The difference was nonsignificant $(\mathrm{p}=0.09)$. In comparison, mean cord blood lead levels and ${ }^{206} \mathrm{~Pb}:{ }^{207} \mathrm{~Pb}$ ratio for the southern Quebec newborn population were respectively $0.11 \mu \mathrm{mol} / \mathrm{l}$ ( $95 \% \mathrm{CI}$ : 0.10 to 0.11 ) and 1.166 (range 1.126-1.230; 95\% CI: 1.163 to 1.168 ). The difference observed for cord blood lead concentrations as for the ${ }^{206} \mathrm{~Pb}:{ }^{207} \mathrm{~Pb}$ ratio with the average of all the Inuit samples were statistically significant $(p \leqslant 0.0001)$.

\section{DISCUSSION}

About 7\% of the 475 newborns had a cord blood lead concentration $\geqslant 0.48 \mu \mathrm{mol} / \mathrm{l}$. In comparison, only $0.16 \%$ of a population of 1109 Caucasian newborns surveyed in the same period in the southern regions of the Quebec province had cord blood lead levels equal to or greater than that level. ${ }^{3}$ In both studies, maternal age and tobacco smoking were positively associated with cord blood lead levels. However, these variables explained only a fraction (19\%) of the variance in cord blood lead concentrations in Nunavik.

The blood lead isotope study showed that the average ${ }^{206} \mathrm{~Pb}:{ }^{207} \mathrm{~Pb}$ ratio was significantly lower in the population of newborns from southern Quebec than in a selected group of the Nunavik population. These results indicated that the two populations are probably exposed to different sources of lead. The mean ratio of 1.166 found in the southern population is probably a mixture of atmospheric lead coming from southern Ontario and the USA, and urban lead found in paint, dust, tyres, etc. In the Arctic, the mean ${ }^{206} \mathrm{~Pb}:{ }^{207} \mathrm{~Pb}$ ratio of atmospheric lead is approximately $1.16 .^{4}$ Hence, atmospheric sources cannot explain the mean ratio found in cord blood of Nunavik newborns.

Drinking water is a negligible source of lead exposure for most Canadians. When a lead in drinking water problem arises, it is usually related to water distribution systems constructed and/or soldered with lead. Water samples collected between 1990 and 1998 after flushing the faucets of Nunavik houses $(n=65)$, yielded a geometric mean concentration of $0.009 \mu \mathrm{mol} / \mathrm{l}(0.19 \mu \mathrm{g} / \mathrm{l})$ (Quebec Department of Environment database). Based on this concentration, the daily exposure by water ingestion for Nunavik women can be estimated at $0.05 \mu \mathrm{g} / \mathrm{kg}$ body weight/day, much lower than the
World Health Organisation (FAO/WHO) tolerable daily intake ( $3.5 \mu \mathrm{g} / \mathrm{kg}$ body weight/day). Water consumption is therefore unlikely to explain the high cord blood lead levels found in Nunavik.

Soil and dust contamination are also unlikely to represent significant sources of lead exposure: there are no industrial activities in Nunavik such as smelters, refineries, or battery recycling plants, which are generally associated with high lead soil and dust concentrations. Moreover, almost all houses in Nunavik were built after 1972, when lead addition to paint was banned in Canada.

The main source of lead contamination in Nunavik is very likely related to dietary habits. The Inuit are heavy consumers of meat from wildlife species. However, available data indicate that lead concentrations are low in all wildlife species consumed in Nunavik. ${ }^{6}$ A study using a nutritional diary conducted in Qikiqtarjuak, on Baffin Island to the north of Nunavik, concluded that women of this community had a weekly lead exposure from food ingestion of $4.4 \mu \mathrm{g} / \mathrm{kg}$ body weight/ week, far below the FAO/WHO provisional tolerable weekly intake of $25 \mu \mathrm{g} / \mathrm{kg}$ body weight/week. ${ }^{5}$ Nevertheless, a study carried out among Inuit women as part of a Santé Québec investigation including a nutritional diary, revealed that only two variables were significantly related to blood lead concentrations for women of childbearing age. These variables are the age of the individuals (partial $r^{2}=0.13$ ) and the level of consumption of geese and ducks (partial $r^{2}=0.13$ ). ${ }^{1}$

Lead shots pellets are regularly seen in the digestive system of the Nunavik Inuit when abdominal $x$ ray examinations are performed (personal communication, Dr Normand Tremblay, Nunavik Regional Board of Health and Social Services). Lead shot pellets were also detected in the digestive system of Cree Indians from northern Ontario, Canada. ${ }^{8}$ Studies have shown that ingestion of lead shot or other small metallic lead objects, can result in increased blood lead concentrations. ${ }^{9}$ Only one to two lead shot pellets trapped in the appendix can be sufficient to increase the blood lead concentration to more than 0.48 $\mu \mathrm{mol} / \mathrm{l}{ }^{9}$

The average ${ }^{206} \mathrm{~Pb}:{ }^{207} \mathrm{~Pb}$ ratio for the Inuit newborns was 1.195 with a relatively wide range (1.166-1.230). Lead isotope data were also collected by the Canadian Wildlife Service for lead shot pellets from different brands of shotshell ammunition. $^{10}$ Their results showed that the range of ${ }^{206} \mathrm{~Pb}:{ }^{207} \mathrm{~Pb}$ ratios for pellets from four brands of shotgun cartridges used by Nunavik hunters (personal communication, Dr Daniel Leclerc, Makivic Society) were also very wide (range 1.125-1.233). However, eight of the 10 samples of analysed cartridges yielded relatively high ratios of ${ }^{206} \mathrm{~Pb}:{ }^{207} \mathrm{~Pb}$, 
ranging from 1.164 to 1.233 (six over 1.201). This information, together with epidemiological data which showed an association between blood lead levels in Nunavik women and the consumption of ducks and geese, suggest that the ingestion of lead shots or lead bearing fragments from game meat may be in a large part responsible for the high lead levels found in Nunavik Inuit newborns.

In 1999, in order to protect fauna, the use of lead shot cartridges was banned in Canada for the hunting of migratory birds. During the winter of 1999, public health authorities of Nunavik actively informed Inuit hunters and ammunition retailers about the possible impact of lead shot ammunition on the newborn's blood lead levels. As part of a cohort study in progress in Nunavik newborns on neurobehavioural effects of heavy metals and organochlorine exposure, we were able to gather new information about the cord blood lead levels in three communities from the beginning of 1997 to the beginning of 2001. The geometric mean of 28 newborns born after the public health intervention (April 1999) $(0.12 \mu \mathrm{mol} / \mathrm{l}$; 95\% CI: 0.09 to 0.16$)$ was significantly lower $(p<0.0001)$ than the geometric mean of 214 children (including the 158 children recruited in the monitoring study before 1997) born before this period $(0.20 \mu \mathrm{mol} / \mathrm{l} ; 95 \%$ CI: 0.19 to 0.22$)$. Even after controlling for maternal age, tobacco smoking, and community of residence, the decrease in cord blood lead levels remained significant $(p<0.0001)$. Although preliminary, these results indicate that efforts to reduce lead exposure from game hunting in Nunavik should continue.

The results of this study suggest that lead shots may be a major source of lead exposure for humans that consume hunted game animals. From a public health perspective, use of lead cartridges shotguns (to hunt migratory birds and other small game) should be replaced internationally with a non-toxic metal or alloy. This is particularly important for those populations where game birds constitute an important dietary component.

\section{ACKNOWLEDGEMENTS}

We thank P Ayotte, J-C Belles-Isles, S Bernier, M-F Gagnon, D Leclerc, and $\mathrm{H}$ Shaver for their assistance in different aspects of this study. This work was funded by the Northern Contaminant Program of Indian and Northern Affairs Canada.

\section{Authors' affiliations}

B Lévesque, J-F Duchesne, M Rhainds, G Muckle, F Dallaire, É Dewailly, Unité de recherche en santé publique, Centre de recherche du CHUL-CHUQ, 945, avenue Wolfe, Sainte-Foy, Québec, GiV 5B3, Canada

C Gariépy, GEOTOP, Université du Québec à Montréal, C.P. 8888,

Succ. Centre-ville, Montréal, Québec, H3C 3P8, Canada

P Dumas, Centre de toxicologie du Québec, Pavillon CHUL, Centre Hospitalier Universitaire de Québec, 945, avenue Wolfe, Sainte-Foy, Québec, GIV 5B3, Canada

A M Scheuhammer, Canadian Wildlife Service, National Wildlife Research Centre, 100 Gamelin Boulevard, Hull, Québec, K1A OH3, Canada

J-F Proulx, Nunavik Board of Health and Social Services, 2400 d'Estimauville, Beauport, Québec, G1E 7G9, Canada S Déry, Nunavik Board of Health and Social Services, 4, rue Rogers Lane, Drummondville, Québec, J2C 1 H8, Canada

Correspondence to: $\operatorname{Dr} B$ Lévesque, Unité de recherche en santé publique du CHUL-CHUQ, 945, avenue Wolfe, Sainte-Foy, Québec, G1V 5B3, Canada; Benoit.Levesque@crchul.ulaval.ca

Accepted 11 October 2002

\section{REFERENCES}

1 Dewailly E, Ayotte P, Bruneau S, et al. Exposure of the Invit population of Nunavik (Arctic Quebec) to lead and mercury. Arch Environ Health $2001 ; 56: 350-7$.

2 Health Canada. Update of evidence for low-level effects of lead and blood lead intervention levels and strategies. Ottawa: The Federal/Provincial Committee on Environmental and Occupational Health, 1994.

3 Rhainds $M$, Levallois $P$, Dewailly É, et al. Lead, mercury, and organochlorine compound levels in cord blood in Québec, Canada. Arch Environ Health 1999:54:40-7.

4 Sturges WT, Barrie LA. Stable lead isotope ratios in Arctic aerosols: evidence for the origin of Arctic air pollution. Atmos Environ 1989:23:2513-19.

5 FAO/WHO. Summary and conclusions. In: Joint FAO/WHO Expert Commitee on Food Additives. Fifty-third Meeting. Rome, 1-10 June 1999:21

6 AMAP. AMAP Assessment report: Arctic pollution issues, vol xii. Oslo, Norway: Arctic Monitoring and Assessment Programme (AMAP), 1998.

7 Chan HM, Kim C, Khoday K, et al. Assessment of dietary exposure to trace metals in Baffin Invit food. Environ Health Perspect 1995; 103:740-6.

8 Tsuji LJS, Nieboer E. Lead pellet ingestion in first nation Cree of the Western James Bay region of Northern Ontario, Canada: implication for a nontoxic shot alternative. Ecosystem Health 1997;3:54-61.

9 Madsen HHT, Skjodt T, Jorgensen PJ, et al. Blood lead levels in patients with lead shot retained in the appendix. Acta Radiol 1988:29:745-6.

10 Scheuhammer AM, Templeton DM. Use of stable isotope ratios to distinguish sources of lead exposure in wild birds. Ecotoxicology 1998;7:37-42 